\title{
Effect of Functional Fitness Training Combined With Yogic Practices on Selected Physical and Physiological Variables of Homemakers
}

\author{
Prof. Vasanthi Kadhiravan"
}

Department of Physical Education University of Mumbai Kalina, Mumbai-400098, India

DOI: $10.36348 /$ jaspe.2020.v03i08.003

| Received: 27.07.2020 | Accepted: 03.08.2020 | Published: 09.08.2020

*Corresponding author: Prof. Vasanthi Kadhiravan

Abstract

Functional training is a classification of exercise which involves training the body for the activities performed in daily life. Yoga is an ancient Indian way of life, which includes changes in mental attitude, diet, and the practice of specific techniques such as yoga asanas (postures), breathing practices (pranayamas), and meditation to attain the highest level of consciousness. This study was conducted with the purpose to find out the combined effect of functional fitness training with yogic practices on selected physical and physiological variables of homemakers. Parallel group experimental design was formulated for this study. The selected 40 homemakers were randomly divided into two equal groups 20 on each group. (Experimental \& Control group). The package of combined functional fitness training with yogic practices was incorporated to the experimental group, for 12 weeks, weekly three days, one hour in the evening session. The pre and post tests were conducted on the selected physical (flexibility, CVE) and Physiological variables (Pulse rate, BP \& lung capacity) on the subjects of both the groups administering standardized tests of sit and reach, 9 minutes run and walk test, manual, monitary and wet spirometry. The collected data was analyzed by using the following statistical tests. The pretest and post test scores were subjected to statistical analysis using paired ' $t$ ' test and in all cases 0.05 level of significance was fixed to test hypothesis. Functional fitness training associated with yogic practices showed a significant contribution to improve the Flexibility, Cardio Vascular Endurance, lung capacity and maintain Blood pressure and Pulse rate.

Keywords: Functional training, yogic practices, flexibility, CVE.

Copyright @ 2020: This is an open-access article distributed under the terms of the Creative Commons Attribution license which permits unrestricted use, distribution, and reproduction in any medium for non-commercial use (NonCommercial, or CC-BY-NC) provided the original author and source are credited.

\section{INTRODUCTION}

Functional training focuses on enhancing your ability to do real-life activities, not just lifting a certain amount of weight in an idealized posture on a gym machine. Functional fitness exercises are designed to train and develop your muscles to make it easier and safer to perform everyday activities, such as carrying groceries, gardening, going up or down stairs, or playing a game with your grandkids. Functional training attempts to adapt or develop exercises which allow individuals to perform the activities of daily life more easily and without injuries [1]. In the context of body building, functional training involves mainly weight bearing activities targeted at core muscles of the abdomen and lower back. Functional training exercise is the latest buzzword in fitness, and for good reason [2].

Yoga is the ancient cultural heritage of our country. It is the universal religious way of our life, which is above all castes, creeds, languages, religions and nations. No other activity in the modern world provides for the human beings the health yoga does. Asana is a very ancient practice of yoga. We find its antiquity even from the excavations of the statues and figures at Mohenjodaro and Harappa [3]. Asanas play an important role in every kind of yoga sadhana.

\section{Yoga for women \\ Yoga is a means to achieving sanity and serenity in their trying and taxing world. Simple breathing techniques will help females calm down and handle their multiple responsibilities with proficiency and poise. It lends balance to the mind and nourishment to the soul. Yoga is highly recommended for females in their adolescence. This tumultuous period shapes the entire lifetime of young girls as they undergo major changes in their body and mind [4]. Today's female is much more than her traditional role of a housewife, a mother or a daughter. Her extended roles that foray beyond her four walls, she plays an equal role in the}


decisions of socioeconomic and political life she leads. She is a multi-faceted, dynamic and uniquely influential part of our society and is forever striving for perfection in every aspect of life. Yoga is ideal exercise for females. Females go through various physical changes during the years of conception and motherhood. Yoga helps optimize productivity for female. Yoga for female can take care most of the common health issues affecting them. Females who practice yoga tend to have lower body mass indexes and better control over their weight than those who do not practice yoga. Middle-age for females comes with its own set of complexities. The benefits of yoga during this time are substantial [5].

Yoga practice provides natural relaxation which is not available with any other exercise. Yoga exercises stimulate all the body organs and endocrine glands. Regular practice will help to maintain physical, mental, and emotional health. Specifically, practicing Yoga, Pranayama and Meditation, during the menopausal phase helps to balance hormones, keep weight under control, avoid medical complications like thyroid, and maintain a healthy digestive system. Regular practice of certain specific asana (postures) ease labor, speed recovery and restore energy levels specific yoga exercises can help us with pregnancy and subsequent recovery postpartum. It plays the role of a "healer" for a new set of physical changes in a female [6].

Yoga for women works on both the mind and body. It makes them strong both physically and emotionally to handle the challenges of life [7].

\section{Benefits of functional fitness}

Besides making one better-rounded as a person, functional fitness has a number of benefits. These include benefits for our health, everyday life, and athletic performance. Following are the five major benefits of functional fitness:

Improves everyday life by improving the overall function of our body, boosting muscle strength and endurance, and developing muscle and body stability, everyday activities can be completed with ease. "Compared to conventional training, the benefits of functional fitness tend to out-weigh everything else because it's actually targeting the movements we are doing every day [8]." In addition, functional fitness improves overall quality of life due to the stress relief factor. This type of training is usually more fun than others since you are essentially training for your everyday life [9].

- Greater muscle memory by performing regular functional fitness exercises we are not just building muscle and core strength, but actually exercising the brain too - effectively boosting our brain's memory.

- Increased mobility: Functional fitness helps to improve balance, coordination, flexibility, muscle strength, and agility. All of these components will leave you more mobile, which in turn helps with our day-to-day life.

- Improves balance and posture: Since functional fitness is all about training the body to make the muscles work together instead of targeted training, overall strength and balance will improve. Training the muscles to manage weight properly will also reduce stress on the body. In turn, posture will be improved.

- Reduced risk of injury: By mimicking the movements done in everyday life, the body is more likely to be able to withstand stressors. Functional fitness training encourages muscle and ligament strength, which are the areas that are highly susceptible to injury.

\section{OBJECTIVES OF THE STUDY}

- To explore the functional fitness program with yogic practices on flexibility, cardio vascular endurance, pulse rate, blood pressure and lung capacity of home makers.

- To design specific fitness programme and yogic practice schedules on the basis of their identified problems;

- To suggest some measures and guidelines for a more fruitful and healthy life of urban housewives.

\section{HYPOTHESES OF THE STUDY}

$\mathrm{H}_{1}$ : Functional fitness training associated with yogic practices will contribute to improve the flexibility of homemakers.

$\mathrm{H}_{2}$ : Functional fitness training associated with yogic practices will contribute to improve the cadio vascular endurance of homemakers.

$\mathrm{H}_{3}$ : Functional fitness training associated with yogic practices will contribute to improve the pulse rate of homemakers.

$\mathrm{H}_{4}$ : Functional fitness training associated with yogic practices will contribute to maintain the blood pressure of homemakers.

$\mathrm{H}_{5}$ : Functional fitness training associated with yogic practices will contribute to improve the lung capacity of homemakers.

\section{SIGNIFICANCES OF THE STUDY}

- The finding of this study will help home makers to understand and assess the comparative changes in physical and physiological components due to functional fitness and yogic practices.

- The study as such will create significant health awareness especially among home makers.

- The study would suggest some measures and guidelines to improve the daily lifestyle of home makers. 


\section{EXPERIMENTAL SECTION: METHODOLOGY}

Selection of Subjects: In this study 40 home makers were randomly selected from Kalina Campus of University of Mumbai as the subjects for this study [10]. The subject's age ranged between 35 to 45 years.

Research Design: Parallel group experimental design was formulated for this study. The selected 40 homemakers were randomly divided into two equal groups 20 on each group. (Experimental \& control group). The package of combined functional fitness training with yogic practices was incorporated to the experimental group, for 12 weeks, weekly three days, one hour in the evening session. The pre and post tests were conducted on the selected physical (flexibility, CVE) and Physiological variable (Pulse rate, BP \& lung capacity) on the subjects of both the groups administering standardized tests of sit and reach, 9 minutes run and walk test, manual, monitary and wet spirometry.

Training schedule phase-i (weeks 1- 12)

\begin{tabular}{|l|c|c|c|}
\hline Exercises & Set & Repetition & Duration \\
\hline Yogic practices & & & \\
\hline Prayer,Om Chanting, Pranayama, stretches & & & 10 mins \\
\hline $\begin{array}{l}\text { Anulom-Vilom, Ujjayi Pranayam } \\
\text { BhastrikaPranayam, Kapalbhati } \\
\text { Suryanamaskar,Selected Asanas }\end{array}$ & 1 & 4 & 20 mins \\
\hline Functional Fitness exercises & & & 20 mins \\
\hline $\begin{array}{l}\text { Lunges, Pushups, Squats. } \\
\text { Burpees, planks, standing overhead dumbbells, } \\
\text { situps, glute bridge, yoga squat, sumo squat }\end{array}$ & 1 & 4 & 10 mins \\
\hline Cool down \& Shavasana & 1 & & \\
\hline
\end{tabular}

\section{STATISTICAL PROCEDURE}

The collected data was analyzed by using the following statistical tests. The pre-test and post test scores were subjected to statistical analysis using paired ' $\mathrm{t}$ ' test and in all cases 0.05 level of significance was fixed to test hypothesis.

\section{RESULTS AND DISCUSSIONS}

The collected data was analyzed by using the following statistical tests. The pre-test and post test scores were subjected to statistical analysis using paired ' $\mathrm{t}$ ' test and in all cases 0.05 level of significance was fixed to test hypothesis [11-13]. The statistical analysis has been presented in the tubular and graphical form with the interpretations.

\section{Result of flexibility of experimental and control group of home makers}

Table-1: Comparison of mean of the Pre \& Post Test Scores of Flexibility of Home Makers

\begin{tabular}{|c|c|c|c|c|}
\hline & Experimental Group & \multicolumn{2}{c|}{ Control Group } \\
\hline & Pre Test & Post Test & Pre Test & Post Test \\
\hline Mean & $\mathbf{1 0 . 0 5}$ & $\mathbf{1 2 . 8 0}$ & $\mathbf{8 . 5 0}$ & $\mathbf{7 . 9 5}$ \\
\hline SD & $\mathbf{2 . 5 2}$ & $\mathbf{3 . 0 0}$ & $\mathbf{2 . 7 2}$ & $\mathbf{2 . 9 5}$ \\
\hline SEM & $\mathbf{0 . 5 6}$ & $\mathbf{0 . 6 7}$ & $\mathbf{0 . 6 1}$ & $\mathbf{0 . 6 6}$ \\
\hline N & $\mathbf{2 0}$ & $\mathbf{2 0}$ & $\mathbf{2 0}$ & $\mathbf{2 0}$ \\
\hline Df & \multicolumn{2}{|c|}{$\mathbf{3 . 0 0 0 0}$} & 19 & $\mathbf{1 . 5 9 9 2}$ \\
\hline T & $\mathbf{6 . 0 0 7 4}$ & \multicolumn{2}{c|}{$\mathbf{0 . 1 2 6 3}$} \\
\hline P & $\mathbf{0}$ &
\end{tabular}

From the above tabulation it can be stated that the calculated mean of flexibility for the Experimental group ( Pre test $-\mathrm{M}=10.05$, Post Test $-\mathrm{M}=12.80$ ) Control group (Pre test $-\mathbf{M}=108.50$, Post Test $-\mathrm{M}=$ 7.95) The standard deviation for the experimental group (SD- Pre Test $-2.52 \&$ Post Test -3.00 ) control group (SD - Pre test $-2.72 \&$ Post test -2.95$)$. The calculated $t$ value for the experimental group ' $t$ ' $=3.0$ with degree of freedom $\mathrm{df}=19$ and $\mathrm{P}$ value $<0.001$. The calculated $\mathrm{t}$ value for the control group ' $\mathrm{t}$ ' $=1.5$, with degree of freedom $\mathrm{df}=19$ and the $\mathrm{P}$ value $=0.1263$. The test has been proved statistically significant at 0.5 level of significant. 


\section{Graph 1. Flexibility of Home Makers}

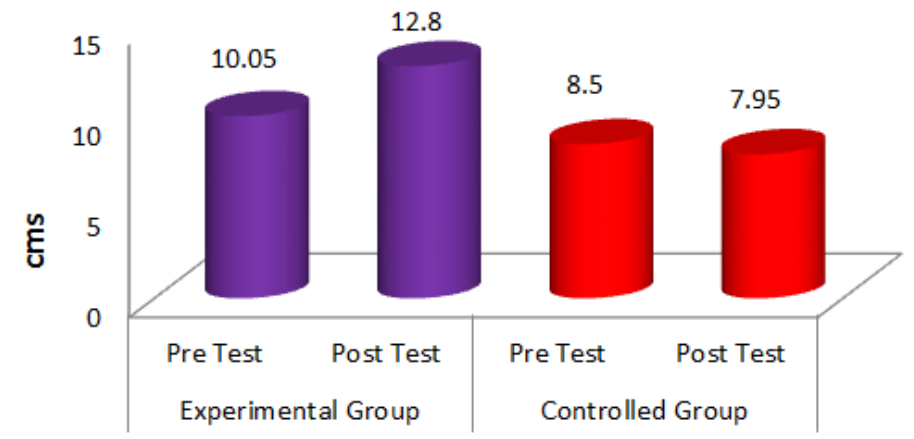

Result of cardio vascular endurance of experimental and control group of home makers

Table-2: Comparison of mean of the Pre \& Post Test Scores of CVE of Home Makers

\begin{tabular}{|c|c|c|c|c|}
\hline 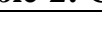 & \multicolumn{2}{|c|}{ Experimental Group } & \multicolumn{2}{|c|}{ Control Group } \\
\hline & Pre Test & Post Test & Pre Test & Post Test \\
\hline Mean & 1102.00 & 1158.50 & 1008.00 & 1006.75 \\
\hline SD & 139.46 & 135.38 & 193.59 & 186.05 \\
\hline SEM & 31.18 & 30.27 & 43.29 & 41.60 \\
\hline $\mathbf{T}$ & \multicolumn{2}{|c|}{5.2865} & \multicolumn{2}{|c|}{0.1304} \\
\hline df & \multicolumn{2}{|c|}{19} & \multicolumn{2}{|c|}{19} \\
\hline $\mathbf{P}$ & \multicolumn{2}{|c|}{$<0.001$} & \multicolumn{2}{|c|}{$=0.8976$} \\
\hline
\end{tabular}

From the above tabulation it can be stated that the calculated mean of CVE for the Experimental group ( Pre test $-\mathrm{M}=1102$, Post Test $-\mathrm{M}=1158.50$ ) Control group (Pre test $-\mathrm{M}=1008$, Post Test $-\mathrm{M}=1006.75$ ) The standard deviation for the experimental group (SD Pre Test $-139.46 \&$ Post Test - 135.38) control group (SD - Pre test $-193.59 \&$ Post test -186.05$)$. The calculated $t$ value for the experimental group ' $t$ ' $=5.28$ with degree of freedom $\mathrm{df}=19$ and $\mathrm{P}$ value $<0.001$. The calculated $t$ value for the control group ' $t$ ' $=1304$ with degree of freedom $\mathrm{df}=19$ and the $\mathrm{P}$ value $=0.8976$, the test has been proved statistically significant at 0.5 level of significant.

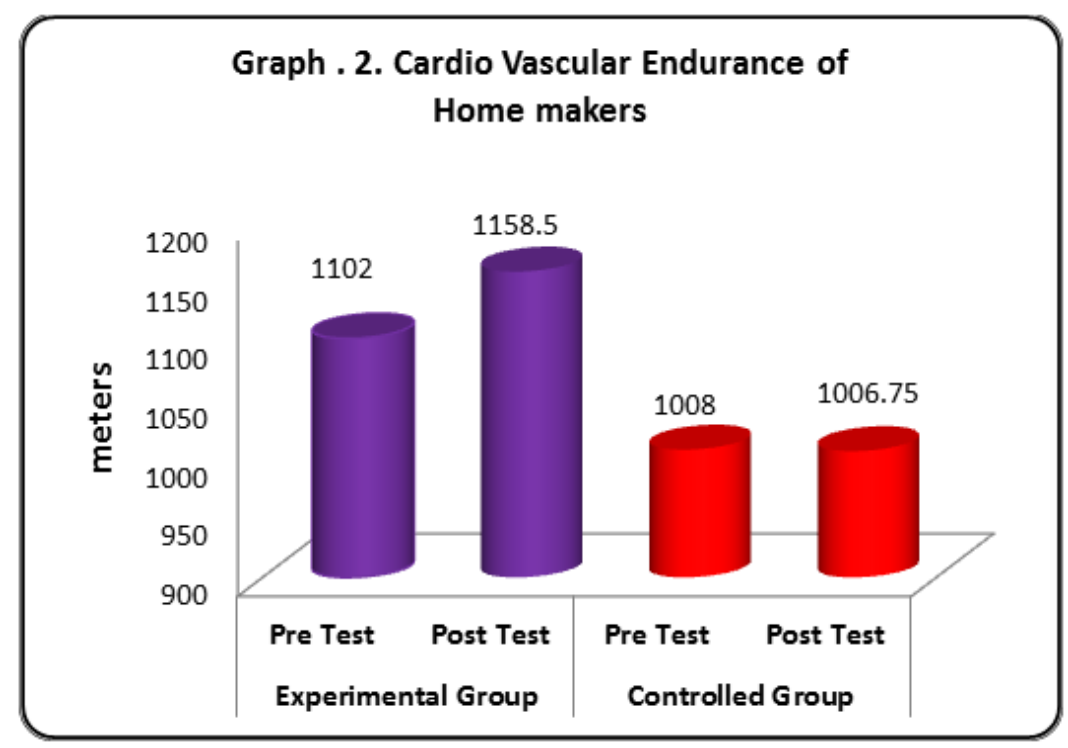




\section{Result of systolic pressure of experimental and control group of home makers}

Table-3: Comparison of mean of Pre \& Post Test Scores of Systolic pressure of Home Makers

\begin{tabular}{|c|c|c|c|c|}
\hline & \multicolumn{2}{|c|}{ Experimental Group } & \multicolumn{2}{c|}{ Controlled Group } \\
\hline & Pre Test & Post Test & Pre Test & Post Test \\
\hline Mean & $\mathbf{1 0 8 . 6 0}$ & $\mathbf{1 0 0 . 7 5}$ & $\mathbf{1 1 7 . 2 0}$ & $\mathbf{1 1 1 . 5 5}$ \\
\hline SD & $\mathbf{9 . 6 0}$ & $\mathbf{1 0 . 5 3}$ & $\mathbf{1 8 . 9 6}$ & $\mathbf{9 . 9 8}$ \\
\hline SEM & $\mathbf{2 . 1 5}$ & $\mathbf{2 . 3 6}$ & $\mathbf{4 . 2 4}$ & $\mathbf{2 . 2 3}$ \\
\hline N & $\mathbf{2 0}$ & $\mathbf{2 0}$ & $\mathbf{2 0}$ & $\mathbf{2 0}$ \\
\hline Df & \multicolumn{2}{|c|}{$\mathbf{6 . 3 9 5 2}$} & \multicolumn{2}{c|}{$\mathbf{1 . 4 2 7 1}$} \\
\hline T & \multicolumn{2}{|c|}{$\mathbf{0 . 0 0 1}$} & \multicolumn{2}{c|}{$\mathbf{0 . 1 6 9 8}$} \\
\hline P & \multicolumn{2}{c|}{} \\
\hline
\end{tabular}

From the above tabulation it can be stated that the calculated mean of systolic blood pressure for the Experimental group (Pretest $-\mathrm{M}=108.60$, Post Test$\mathrm{M}=100.75$ ) Control group (Pre test $-\mathrm{M}=117.20$, Post Test $-M=111.55)$ The standard deviation for the experimental group (SD - Pre Test - $9.60 \&$ Post Test 10.53) control group (SD - Pre test $-18.96 \&$ Post test
- 9.96). The calculated $\mathrm{t}$ value for the experimental group ' $\mathrm{t}$ ' $=6.39$ with degree of freedom $\mathrm{df}=19$ and $\mathrm{P}$ value $<0.001$. The calculated $t$ value for the control group ' $\mathrm{t}$ ' $=1.42$ with degree of freedom $\mathrm{df}=19$ and the $\mathrm{P}$ value $=0.1698$. The test has been proved statistically significant at 0.5 level of significant.

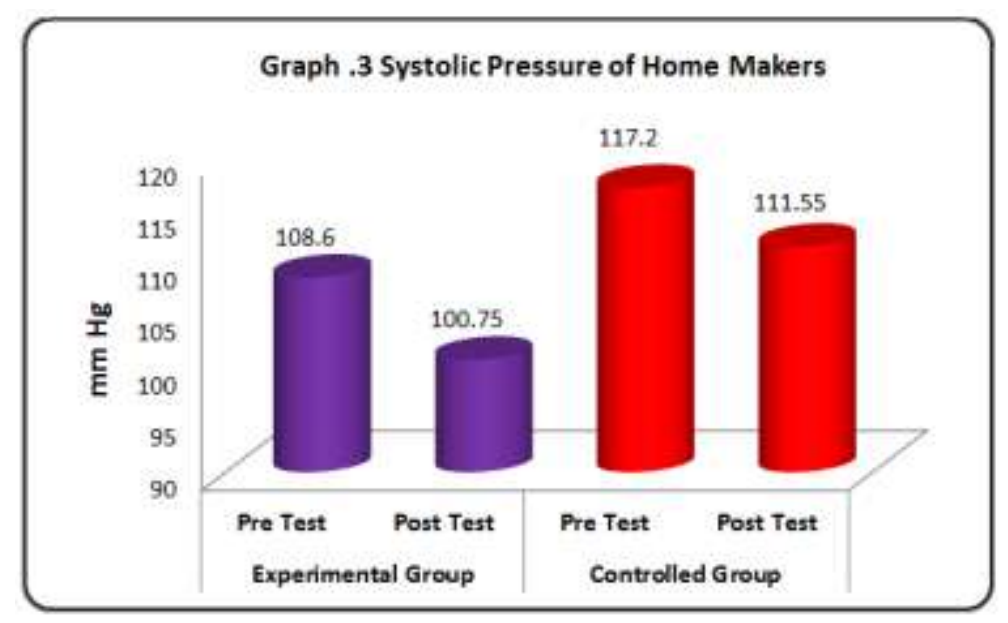

Result of diastolic pressure of experimental and control group of home makers

Table-4: Comparison of mean of pre and posttest of the Diastolic pressure of Home Makers

\begin{tabular}{|c|c|c|c|c|}
\hline & \multicolumn{2}{|c|}{ Experimental Group } & \multicolumn{2}{c|}{ Control Group } \\
\hline & Pre Test & Post Test & Pre Test & Post Test \\
\hline Mean & $\mathbf{7 2 . 3 0}$ & $\mathbf{6 9 . 8 5}$ & $\mathbf{7 1 . 6 5}$ & $\mathbf{7 2 . 8 0}$ \\
\hline SD & $\mathbf{1 4 . 7 4}$ & $\mathbf{1 1 . 0 1}$ & $\mathbf{9 . 4 7}$ & $\mathbf{4 . 7 0}$ \\
\hline SEM & $\mathbf{3 . 3 0}$ & $\mathbf{2 . 4 6}$ & $\mathbf{2 . 1 2}$ & $\mathbf{1 . 0 5}$ \\
\hline N & $\mathbf{2 0}$ & $\mathbf{2 0}$ & $\mathbf{2 0}$ & $\mathbf{2 0}$ \\
\hline Df & \multicolumn{2}{|c|}{$\mathbf{1 . 7 2 3 1}$} & \multicolumn{2}{c|}{$\mathbf{2 . 0 0 2 6}$} \\
\hline T & \multicolumn{2}{|c|}{$\mathbf{0 . 1 0 1 1}$} & \multicolumn{2}{c|}{$\mathbf{c 5 5 9 7}$} \\
\hline P & \multicolumn{2}{c}{} \\
\hline
\end{tabular}

From the above tabulation it can be stated that the calculated mean of systolic blood pressure for the Experimental group (Pre test $-\mathrm{M}=72.69$ Post Test $\mathrm{M}=69.85$ ) Control group (Pre test $-\mathrm{M}=71.65$, Post Test $-\mathrm{M}=72.80)$ The standard deviation for the experimental group (SD - Pre Test -14.74 \& Post Test - 11.01) control group (SD - Pre test $-9.47 \&$ Post test -
4.70). The calculated $t$ value for the experimental group ' $\mathrm{t}$ ' $=1.72$ with degree of freedom $\mathrm{df}=19$ and $\mathrm{P}$ value $<0.001$. The calculated $\mathrm{t}$ value for the control group ' $\mathrm{t}$ ' $=2.00$ with degree of freedom $\mathrm{df}=19$ and the $\mathrm{P}$ value $=0.059$ The test has been proved statistically significant at 0.5 level of significant. 


\section{Graph . 4 Diastolic Pressure of Home Makers}

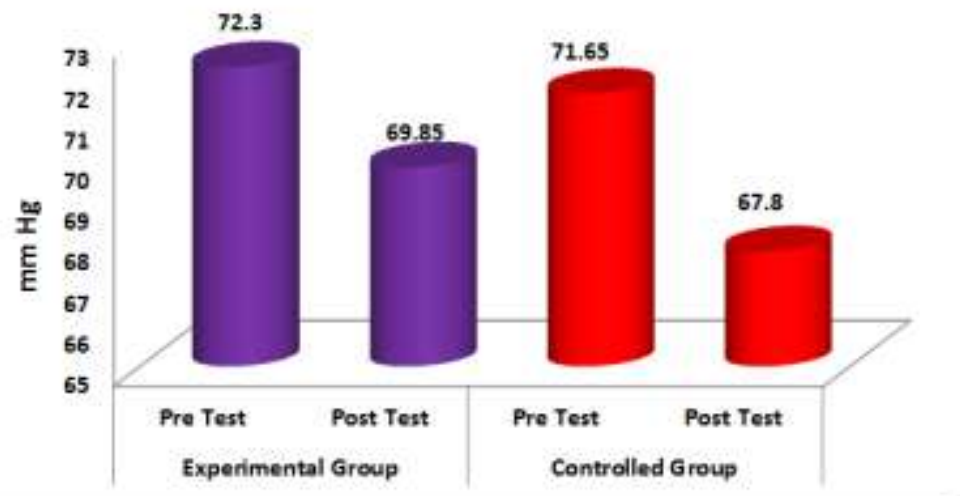

Result of pulse rate of experimental and control group of home makers

Table-5: Comparison of mean of pre and post tests of the Pulse Rate of Home Makers

\begin{tabular}{|c|c|c|c|c|}
\hline & \multicolumn{2}{|c|}{ Experimental Group } & \multicolumn{2}{|c|}{ Control Group } \\
\hline & Pre Test & Post Test & Pre Test & Post Test \\
\hline Mean & 91.45 & 85.90 & 98.10 & 93.30 \\
\hline SD & 13.25 & 10.25 & 15.14 & 14.68 \\
\hline SEM & 2.96 & 2.29 & 3.39 & 2.28 \\
\hline $\mathbf{N}$ & 20 & 20 & 20 & 20 \\
\hline Df & \multicolumn{2}{|c|}{19} & \multicolumn{2}{|c|}{19} \\
\hline $\mathbf{T}$ & \multicolumn{2}{|c|}{3.1193} & \multicolumn{2}{|c|}{1.6548} \\
\hline $\mathbf{P}$ & \multicolumn{2}{|c|}{$=0.0056$} & \multicolumn{2}{|c|}{$=0.1144$} \\
\hline
\end{tabular}

From the above tabulation it can be stated that the calculated mean of pulse rate for the Experimental group ( Pre test $-\mathrm{M}=91.45$, Post Test $-\mathrm{M}=85.90$ ) Controlled group (Pre test $-\mathrm{M}=98.1$ Post Test $-\mathrm{M}=$ 93.3) The standard deviation for the experimental group ( SD - Pre Test -13.25 \& Post Test - 10.25) controlled group (SD - Pre test $-15.14 \&$ Post test -14.68 ). The calculated $t$ value for the experimental group ' $t$ ' $=3.11$ with degree of freedom $\mathrm{df}=19$ and $\mathrm{P}$ value $<0.001$. The calculated $t$ value for the controlled group ' $t$ ' $=1.65$ with degree of freedom $\mathrm{df}=19$ and the $\mathrm{P}$ value $=$ 0.1144 . The test has been proved statistically significant at 0.5 level of significant.

\section{Graph.5 Pulse Rate of Home Makers}

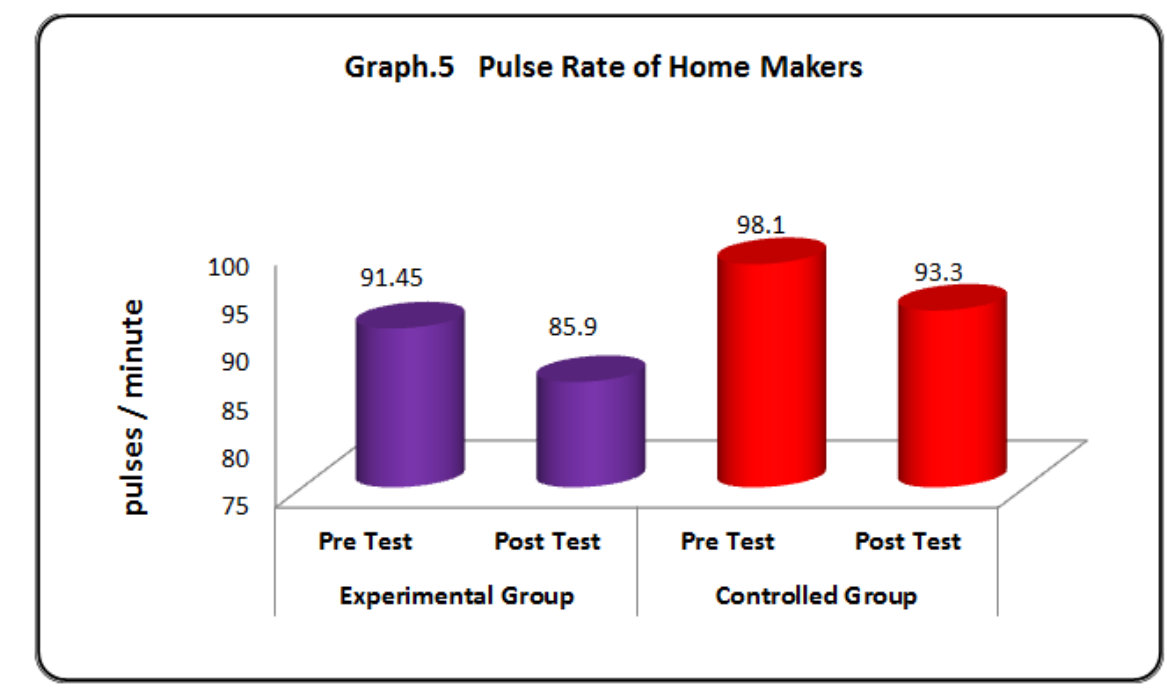




\section{Result of lung capacity of experimental and control group of home makers}

Table-6: Comparison of mean of the Lung Capacity of Home Makers

\begin{tabular}{|c|c|c|c|c|}
\hline & \multicolumn{2}{|c|}{ Experimental Group } & \multicolumn{2}{c|}{ Control Group } \\
\hline & Pre Test & Post Test & Pre Test & Post Test \\
\hline Mean & $\mathbf{3 . 8 8 0}$ & $\mathbf{4 . 2 0 0}$ & $\mathbf{3 . 8 8 5}$ & $\mathbf{3 . 8 8 0}$ \\
\hline SD & $\mathbf{0 . 3 9 6}$ & $\mathbf{0 . 3 5 5}$ & $\mathbf{0 . 4 2 8}$ & $\mathbf{0 . 7 3 3}$ \\
\hline SEM & $\mathbf{0 . 0 8 8}$ & $\mathbf{0 . 0 7 9}$ & $\mathbf{0 . 0 9 6}$ & $\mathbf{0 . 1 6 4}$ \\
\hline N & $\mathbf{2 0}$ & $\mathbf{2 0}$ & $\mathbf{2 0}$ & $\mathbf{2 0}$ \\
\hline Df & \multicolumn{2}{|c|}{$\mathbf{9 . 0 0 0 0}$} & \multicolumn{2}{c|}{1.4277} \\
\hline T & \multicolumn{2}{|c|}{$\mathbf{0 . 0 0 0 1}$} & \multicolumn{2}{c|}{$\mathbf{0 . 1 6 9 6}$} \\
\hline P & \multicolumn{2}{c|}{} \\
\hline
\end{tabular}

From the above tabulation it can be stated that the calculated mean of lung capacity for the Experimental group (Pre test $-\mathrm{M}=3.880$, Post Test$\mathrm{M}=4.200$ ) Controlled group (Pre test $-\mathrm{M}=3.885$, Post Test $-\mathrm{M}=3.880$ ) The standard deviation for the experimental group ( SD - Pre Test $-0.396 \&$ Post Test $-0.355)$ controlled group (SD - Pre test $-0.428 \&$ Post test - 0.733). The calculated $t$ value for the experimental group ' $t$ ' $=9.0000$ with degree of freedom $\mathrm{df}=19$ and $\mathrm{P}$ value $<0.001$. The calculated $\mathrm{t}$ value for the controlled group ' $t$ ' $=1.42$ with degree of freedom $\mathrm{df}=19$ and the $\mathrm{P}$ value $=0.1696$. The test has been proved statistically significant at 0.5 level of significant.

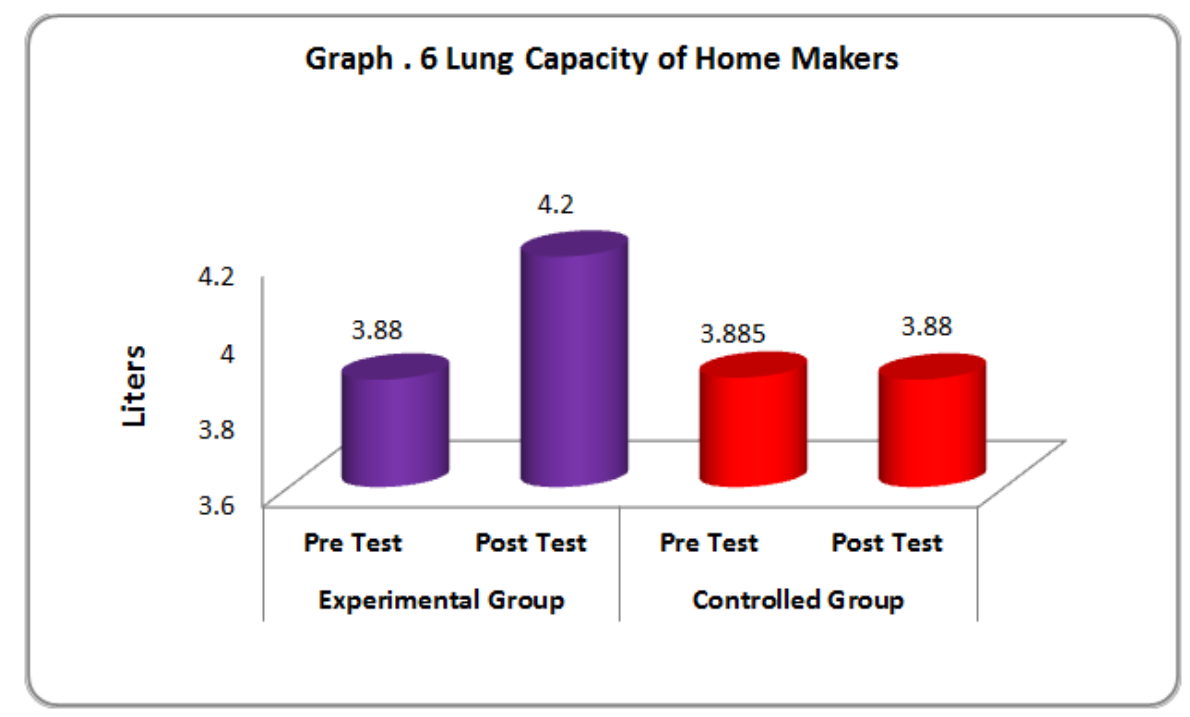

\section{CONCLUSIONS}

- Functional fitness training associated with yogic practices showed a significant contribution to improve the flexibility of homemakers.

- Functional fitness training associated with yogic practices showed a significant contribution to improve the Cardio Vascular Endurance of homemakers

- Functional fitness training associated with yogic practices showed a significant contribution to maintain the systolic pressure of homemakers

- Functional fitness training associated with yogic practices showed a significant contribution to maintain the diastolic pressure of homemakers

- Functional fitness training associated with yogic practices showed a significant contribution to maintain pulse rate of the of homemakers

- Functional fitness training associated with yogic practices showed a significant contribution to improve lung capacity of homemakers

\section{REFERENCE}

1. American Academy of Pediatrics. (1987). Committees on Sports Medicine and School Health. Physical fitness and the schools. Pediatrics, 80, 449-450.

2. Bera, T. K., \& Rajapurkar, M. V. (1993). Body composition, cardiovascular endurance and anaerobic power of yogic practitioner. Indian Journal of Physiology and Pharmacology, 37, 225225.

3. Clark, J.K. (1989). Flexibility and Statistical Technique: For the purpose of analysis of data descriptive statistics (mean and standard deviation) and parallel group independent ' $t$ ' test was applied. The collected data were finally tabulated, analyzed and conclusion has been drawn.

4. Gait changes in the elderly as a result of participation in a prescribed exercise program. Completed Research in Health, Physical Education, Recreation \& Dance, 31, 262-263. 
5. Cox, K. L., Burke, V., Morton, A. R., Gillam, H. F., Beilin, L. J., \& Puddey, I. B. (2001). Long-term effects of exercise on blood pressure and lipids in healthy women aged 40-65 years: The Sedentary Women Exercise Adherence Trial (SWEAT). Journal of hypertension, 19(10), 17331743.

6. Fahlman, M. M., Boardley, D., Lambert, C. P., \& Flynn, M. G. (2002). Effects of endurance training and resistance training on plasma lipoprotein profiles in elderly women. The Journals of Gerontology Series A: Biological Sciences and Medical Sciences, 57(2), B54-B60.

7. Breslow, L. (1990). "A health promotion primer for the 1990's". Health Affairs (Summer), 6-21.

8. Caspersen, C. J., Christenson, G. M., \& Pollard, R. A. (1986). Status of the 1990 physical fitness and exercise objectives--evidence from NHIS 1985. Public health reports, 101(6), 587.

9. Stephens, T., Jacobs Jr, D. R., \& White, C. C. (1985). A descriptive epidemiology of leisure-time physical activity. Public health reports, 100(2), 147.

10. Sallis, J.F., \& McKenzie, T.L. (1991). Op cit, 62, 2, 124-137.

11. http://www.ijoy.org.in/

12. https://www.researchgate.net/publication/30549794 6_Effects_of_eight_weeks_of_functional_training in_the_functional_autonomy_of_elderly_women_ A_pilot_study

13. https://www.ncbi.nlm.nih.gov/pmc/articles/PMC44 $16638 /$ 